Article

\title{
Governance Strategies for Improving Flood Resilience in the Face of Climate Change
}

\author{
Peter P. J. Driessen ${ }^{1}\left(\mathbb{D}\right.$, Dries L. T. Hegger ${ }^{1, * \mathbb{D}}$, Zbigniew W. Kundzewicz ${ }^{2,3}$, \\ Helena F. M. W. van Rijswick ${ }^{4}$, Ann Crabbé ${ }^{5}$, Corinne Larrue ${ }^{6}$, Piotr Matczak ${ }^{7}$ (D), \\ Maria Pettersson ${ }^{8}$, Sally Priest ${ }^{9}$, Cathy Suykens ${ }^{4,10}$, Gerrit Thomas Raadgever ${ }^{11}$ and \\ Mark Wiering ${ }^{12}$
}

1 Copernicus Institute of Sustainable Development, Utrecht University, Princetonlaan 8a, 3584 CB Utrecht, The Netherlands; p.driessen@uu.nl

2 Institute for Agricultural and Forest Environment, Polish Academy of Sciences, Bukowska 19, 60-809 Poznań, Poland; kundzewicz@yahoo.com

3 Potsdam Institute for Climate Impact Research, Telegrafenberg A 31, 14473 Potsdam, Germany

4 Utrecht Centre for Water, Oceans and Sustainability Law, Utrecht University School of Law, Newtonlaan 201, 3584 BH Utrecht, The Netherlands; h.vanrijswick@uu.nl (H.F.M.W.v.R.); c.b.r.suykens@uu.nl or cathy.suykens@kuleuven.be (C.S.)

5 Research Group Environment \& Society, Sociology Department, Faculty of Social Sciences, University of Antwerp, Sint-Jacobsstraat 2, S.M.380, 2000 Antwerp, Belgium; ann.crabbe@uantwerpen.be

6 Paris School of Planning, Lab'Urba, Paris Est University, 14-20 Bd Newton, 77454 Marne La Vallée CEDEX 2, France; corinne.larrue@u-pec.fr

7 Institute of Sociology, Adam Mickiewicz University, ul. Szamarzewskiego 89c, 60-568 Poznań, Poland; matczak@amu.edu.pl

8 Law Unit, Luleå University of Technology, SE-971 87 Luleå, Sweden; maria.pettersson@ltu.se

9 Flood Hazard Research Centre, Middlesex University, The Burroughs, Hendon, London NW4 4BT, UK; s.priest@mdx.ac.uk

10 Institute for Environmental and Energy Law, KU Leuven, Oude Markt 13-bus 5500, 3000 Leuven, Belgium

11 Sweco Netherlands B.V., De Holle Bilt 22, 3743 HM De Bilt, The Netherlands; tom.raadgever@sweco.nl

12 Institute for Management Research, Radboud University Nijmegen, Heyendaalseweg 141, 6525 AJ Nijmegen, The Netherlands; m.wiering@fm.ru.nl

* Correspondence: d.l.t.hegger@uu.nl; Tel.: +31-(0)30-253-7829

Received: 8 October 2018; Accepted: 4 November 2018; Published: 7 November 2018

\begin{abstract}
Flooding is the most common of all natural disasters and accounts for large numbers of casualties and a high amount of economic damage worldwide. To be 'flood resilient', countries should have sufficient capacity to resist, the capacity to absorb and recover, and the capacity to transform and adapt. Based on international comparative research, we conclude that six key governance strategies will enhance 'flood resilience' and will secure the necessary capacities. These strategies pertain to: (i) the diversification of flood risk management approaches; (ii) the alignment of flood risk management approaches to overcome fragmentation; (iii) the involvement, cooperation, and alignment of both public and private actors in flood risk management; (iv) the presence of adequate formal rules that balance legal certainty and flexibility; (v) the assurance of sufficient financial and other types of resources; (vi) the adoption of normative principles that adequately deal with distributional effects. These governance strategies appear to be relevant across different physical and institutional contexts. The findings may also hold valuable lessons for the governance of climate adaptation more generally.
\end{abstract}

Keywords: flood risk management; flood resilience; governance strategies; climate change 


\section{Introduction}

Flood risks are increasing in coastal areas and river basins due to worsening hazards related to urbanization and the effects of climate change [1-6]. Metropolitan regions such as Bangkok, Mumbai, Jakarta, Shanghai, Dhaka, London, Hamburg, and Rotterdam are extremely vulnerable to flooding. Extreme events in the Caribbean, the United States, and Bangladesh in 2017 and Japan, the US, and the Philippines in 2018 show how devastating the effects of floods can be. In response to these risks, an abundance of natural science and technical knowledge has been developed. In scientific literature, the concept of 'resilience' has been introduced as the ultimate and desirable outcome of flood risk management. A well-known definition of resilience is that of Walker et al. (p. 6): "the capacity of a system to absorb disturbances and reorganize while undergoing change, so as to still retain essentially the same function, structure, identity and feedback" [7]. A flood resilient system has in place the capacity to resist floods (e.g., by flood defenses), the capacity to absorb and recover from floods (e.g., by spatial planning, disaster management, insurance), and the capacity to adapt and transform (in order to moderate potential damages, to take advantage of opportunities, and to cope with the consequences of floods and respond in a flexible way) [8,9].

Flood risk management literature is well-grounded in risk assessments and future scenarios and is based on profound insights into the effectiveness of technical measures [10,11]. In contrast, the question of which governance actions should be taken to improve flood resilience has received lesser attention, despite the strong barriers that social and institutional factors often present to successful flood risk management [11-13].

To address this knowledge gap, a comparative analysis and evaluation of flood risk governance was conducted. This took place under the auspices of the STAR-FLOOD project (2012-2016) which was funded through the Seventh Framework program of the European Commission. This was the first large integrated European research project in the floods domain that focused almost entirely on governance and legal issues. The studied countries, namely Belgium, England, France, The Netherlands, Poland, and Sweden, are all European Union (EU) countries in which governments take a significant level of responsibility. This is partly due to the fact that there is EU legislation in place and is also partly for historical and political reasons. The flood risk management practices in these countries were studied, as detailed in the materials and methods section.

The current paper presents the six main governance strategies that the authors identified based on the research that was carried out. After providing the materials and methods in Section 2, Section 3 will subsequently present each of the strategies. We hold that these strategies are relevant across different contexts and have a wider meaning internationally.

\section{Materials and Methods}

In the framework of the STAR-FLOOD project, systematic and detailed analyses and evaluations of flood risk governance and associated legal frameworks in Belgium, England, France, The Netherlands, Poland, and Sweden were conducted between October 2013 and September 2015, which have been laid down, amongst others, in six country reports [14-19]. All partners conducted empirical analyses and evaluations of flood risk governance in their country, both at the national level and at the level of three specific urban areas that were used to illustrate and further explore developments at the national level. The research was based on a common analytical framework. We applied four different research methods in all countries: desk research (analysis of policy documents, legal texts, case law, literature); semi-structured interviews (70 in Belgium, 61 in England, 64 in France, 45 in The Netherlands, 54 in Poland, and 19 in Sweden), legal comparison, and at least one workshop with stakeholders in each country $([20,21]$, p. 14). Similarities and differences between the countries as well as lessons to be derived from them were discussed in plenary meetings and meetings in sub-groups in which the full consortium (>30 policy analysts and legal scholars) participated. These discussions have led to the first syntheses of the findings [20,21]. The author team of the current paper consists of at least one representative from each consortium partner, representing each country and the policy and legal 
disciplines. This team engaged in intensive discussions aimed at further condensing the findings and drawing out the key lessons. Each of the key lessons that are presented in the next sections are backed-up by solid empirical evidence [14-19]. We recognize that the paper's focus on the European context brings limitations in terms of potential generalization of findings to geographical regions other than Europe. Important issues that make these regions different from Europe are the general degree of risk awareness, linked to the population's alphabetization rate, policymakers' skills, and the rate of democracy. These and other issues are in many cases far removed from the European and north American situation. Moreover, a lack of financial resources and the poorness of infrastructure are important complicating factors to establishing efficient flood risk prevention or to build flood defense. Nevertheless, as we will show in Section 3 and conclude upon in Section 4, we believe that our paper's six governance strategies can serve as an important source of inspiration for improving flood risk governance more internationally, even though some of the lessons might need some degree of translation to other geographical contexts. To validate the lessons, the author team reassessed the empirical data and, in some cases, consulted researchers who were not directly involved in writing this paper. The steps above, in our view, ensure a certain robustness, however they also ensure transparency of the findings.

\section{Results: Key Governance Strategies for Enhancing Flood Resilience}

This section subsequently presents each of the six governance strategies that were identified based on the country comparison. The lessons pertain to diversification of flood risk management approaches (3.1), alignment of these approaches (3.2), involvement of private actors in flood risk governance (3.3), the role of formal rules (3.4), the assurance of sufficient resources (3.5), and the presence of adequate normative principles to deal with distributional effects (3.6).

\subsection{Diversification of Flood Risk Management Approaches, Taking into Account the Physical and Institutional Context}

It is increasingly argued that optimizing the capacity to resist floods, absorb and recover from floods, and to adapt and transform requires a diversified portfolio of flood risk management approaches [9,22,23]. We identify five modes of flood risk management: flood prevention; flood defense; flood mitigation; flood preparation and flood recovery (see Table 1).

Table 1. Five modes of flood risk management, adapted from [21,23]. Note that the main distinguishing feature in this categorization is the focus of each mode on reducing the probability of floods, reducing the consequences of floods, or promoting recovery. This is an entry point that differs to the classical one by Thampapillai and Musgrave who use the term flood damage mitigation to refer to all strategies and further distinguish between structural and non-structural measures. In our categorization, structural measures mainly relate to the flood defense strategy [24].

\begin{tabular}{ll}
\hline \multicolumn{1}{|c|}{ Mode } & \multicolumn{1}{c}{ Characteristics } \\
\hline 1. Flood risk prevention & $\begin{array}{l}\text { Prevention measures aim to decrease the exposure of } \\
\text { people/property etc. via methods that prohibit or discourage } \\
\text { development in areas that are at risk of flooding (e.g., spatial } \\
\text { planning, re-allotment policy, expropriation policy etc.). The } \\
\text { main focus of this approach is on "keeping people away from } \\
\text { water" by only building outside flood-prone areas. This is a } \\
\text { pro-active strategy that focuses both on probability reduction (if } \\
\text { people do not live in flood-prone areas, then it is unlikely that } \\
\text { they will get flooded) and the consequences of flooding (an area } \\
\text { may still be flooded, however in the absence of large-scale urban } \\
\text { developments, the consequences are relatively small). }\end{array}$ \\
\hline
\end{tabular}


Table 1. Cont

\begin{tabular}{ll}
\hline 2. Mode & \multicolumn{1}{c}{ Characteristics } \\
\hline Flood defense measures aim to decrease the probability of \\
flooding areas through infrastructural works, such as dikes, \\
dams, embankments and weirs, mostly referred to as "flood \\
defense" or "structural measures" through options that increase \\
the capacity of existing channels for water conveyance (natural \\
or man-made) to increase the space for water (laterally or \\
vertically) or the creation of new spaces for water retention \\
outside of the area to be defended. In brief, the focus is on \\
"keeping water away from people".
\end{tabular}

3. Flood risk mitigation

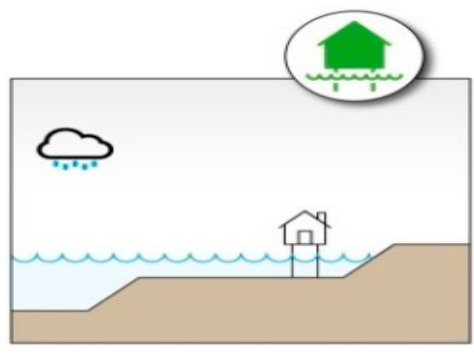

Flood risk mitigation focuses on decreasing the consequences of floods through measures inside the vulnerable area. Consequences can be moderated by a smart design of the flood-prone area. Measures include smart spatial ordering inside urban areas, water retention within the protected area, or (regulations for) flood-proof building. Flood risk mitigation thus includes all measures to flood-proof the built environment as well as measures to retain or store water.

4. Flood preparation

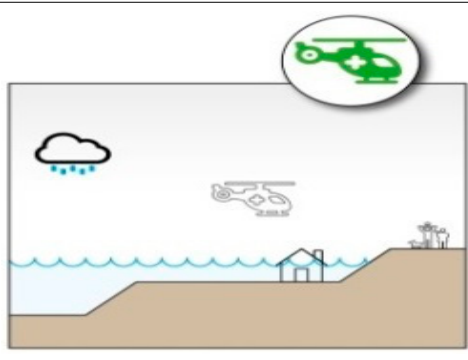

Consequences of floods can also be alleviated by preparing for a flood event. Measures include developing flood forecasting and warning systems, as well as preparing disaster management and evacuation plans.

5. Flood recovery

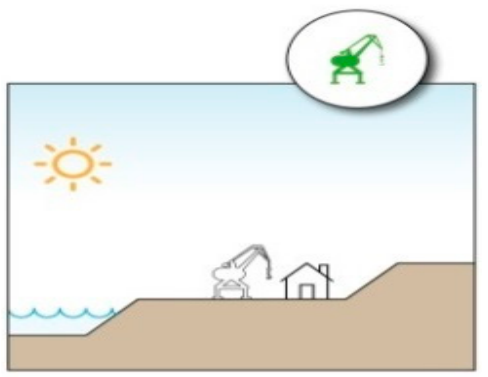

This approach facilitates an effective recovery after a flood event. Measures include reconstruction or rebuilding plans (that may also provide a window of opportunity for making the new buildings more flood-proof or relocate these to safer areas) as well as compensation or insurance systems.

Each of these modes differs in its focus on the reduction of flood probability, flood exposure, and flood consequences, however it is assumed that together these modes will effectively decrease the flood risk $[9,23]$. A diversified portfolio of effectively functioning flood risk management approaches is needed to be able to address the three resilience capacities. The flood defense approach contributes to the capacity to resist, while the other four strategies contribute to the capacity to absorb and recover and the capacity to adapt and transform $[9,23]$.

Countries have their own strengths and weaknesses in terms of the implemented portfolio of flood risk management approaches. This has repercussions for the way in which diversification should be pursued. For instance, Poland and especially The Netherlands show a dominant focus on flood defense. These countries are now facing the challenge of broadening their portfolio to better address 
the potential consequences of flooding. Further development of the complementary strategies to increase flood resilience has proven to be challenging. The Netherlands have gained several centuries of experience fighting against the water. The country's track record regarding flood defense is excellent. Moreover, the flood-defense approach is highly institutionalized [16]. However, over the years, new ideas have started to have more of an impact. From the 1990s onwards, the dominant 'keeping the water out' paradigm has been complemented with Room for the River approaches that can be seen as a broadening within the flood defense strategy. As a next step, in more recent years, the further development of flood mitigation and recovery-and to a lesser extent flood risk prevention-have gained more prominence in policy discourses, while experiments with the new approaches have started [16,25]. In the Polish situation, the dominant tendency was to sort out flood defense first, despite the fact that Polish water management agencies suffer from a severe lack of resources [18]. Amongst other events, the floods of 1997 and 2010 gave an impetus to the development of improved flood forecasting and warning systems. However, the further development of the other strategies is proceeding very gradually. Both in The Netherlands and Poland, there is a relative dominance of flood defense which contributes to path dependency. To some extent, the flood defense strategy is seen as 'inescapable' because developments in flood prone areas-in The Netherlands, a low-lying country, more than half of its surface-have already taken place and are unlikely to be reversed in the short to medium term.

At the other extreme, flood risk management in England has been diversified for several decades and England's portfolio of management approaches has been diagnosed as balanced, as in: showing a high degree of diversity, although the effectiveness of specific approaches was found to need improvement $[9,14]$. This relatively positive evaluation of England's portfolio might come across as counter-intuitive, given that England has experienced several floods in recent years, most notably in 2000, 2007, and 2014. However, a strength of the English flood risk governance arrangement is that it has a range of approaches at its disposal, each of them tailored to specific circumstances in terms of the physical characteristics of an area and the potential for damage and economic loss [14].

Belgium, France, and Sweden are positioned on a spectrum between these two extremes. Both in Belgium and France, there used to be a focus on flood defense, however to a lesser extent than in The Netherlands and Poland. Belgium's prevention and mitigation strategies overtook those of The Netherlands when it started to implement designated policies that aimed to put restrictions on urban development in flood prone areas (including signal areas and the water test) [19]. At the same time, in France, a discursive shift can be observed towards an increased emphasis on flood prevention [17]. Swedish flood risk governance is characterized by a very localized approach with a dominant role for the municipalities as well as the civil contingency agencies. While there are important local variations, there is a strong reliance on flood preparation [15].

Overall, the findings show that a diversification of modes of flood risk management contributes to flood resilience in that it helps to address a broader range of resilience capacities: that to resist, to absorb and recover, and to adapt and transform [9]. However, the extent to which approaches can be diversified depends on physical and institutional features, as well as general levels of development, flood risk management legacies, culture, and politics.

\subsection{Alignment of Flood Risk Management Approaches to Overcome Fragmentation}

To diversify flood risk management approaches, different sectors need to be aligned. Besides water management, spatial planning and emergency management, amongst other sectors, are also necessary to cover the range of approaches from prevention to recovery by providing adequate policy instruments. Hence, enhancing connectivity between policy sectors and administrative levels is needed to overcome the fragmentation that a diversification of flood risk management approaches may create.

Such connectivity requires the employment of bridging mechanisms or processes that broadly entail information exchange, coordination of policies, and cooperation mechanisms [26]. These mechanisms can be anchored through laws and policy instruments and can be promoted through 
finances and by putting knowledge infrastructures in place. Bridging mechanisms may help to establish links between different flood risk management approaches, thus ensuring that these approaches reinforce each other and, hence, help to strengthen all resilience capacities. Two examples include:

- $\quad$ Recovery schemes to compensate victims of a flood event, e.g., through private insurance schemes (possibly in cooperation with the nation state) or the activation of a public fund, can enhance the success of the risk prevention and mitigation strategies and vice versa [26]. Compensation and insurance schemes may incentivize or dis-incentivize citizens and public authorities to undertake flood risk reduction and promote the implementation of property-level measures through risk differentiation, structured premium increases or premium benefits, or resilient reinstatement. For instance, the French system is lauded for its comprehensive recovery scheme through the CAT-NAT ('Natural Disaster' (CATastrophe NATurelle in French) fund, however it was found that this scheme forms a dis-incentive for taking preventative measures [17,27], hampering ongoing efforts to strengthen flood prevention approaches by limiting urban development in flood prone areas. On the other hand, in England, experience has been gained with risk-based insurance premiums, which in some cases have been complemented with premium reductions in case property owners take mitigating measures. In this situation, recovery schemes serve as an incentive for strengthening flood risk prevention and mitigation [14]. Hence, policy instruments that are used in one strategy in a specific country cannot be applied in another jurisdiction without looking at the overall picture of the several strategies and the policy instruments that are related to them [28].

- By analogy, effective flood emergency management requires tailor-made spatial planning policies and probabilistic decision-making processes to improve the effectiveness of evacuation [26]. For instance, the effective evacuation of citizens out of flood-prone areas puts requirements on spatial preconditions such as the presence of elevated evacuation routes and the realization of shelters. In some cases, existing spatial configurations make horizontal evacuation impossible and necessitate the realization of plans for vertical evaluation. This is the case for several low-lying areas in The Netherlands [29].

Besides establishing links between different sectors, bridging mechanisms can also help to link different governance levels. Top-down and bottom-up policy processes should be combined and coordinated. At a strategic level, acceptable levels of risk and the division of responsibilities in dealing with these risks should be discussed [20]. Countries show a different track record in this respect. In England, we see that the Environment Agency is playing a key role in facilitating discussions at the strategic level [14]. The Netherlands have established a national 'Delta program' which stimulates the exchange of ideas and experiences as well as strategic planning with the inclusion of governmental actors at the national level (Rijkswaterstaat, the Dutch Office for Public Works), the Regional Water Authorities, municipalities, and knowledge institutes, among other actors [16]. Such discussions are also held in Belgium, although coordination takes place mostly at the level of the three regions, being the Flanders, Walloon, and Brussels Capital regions, while inter-regional exchange is still in an embryonic stage [19]. In Poland, the new administration body: the National Water Management Holding Polish Waters, was established in 2018 with the intention to consolidate water management, including flood risk management. In Sweden, a lack of strategic discussions at the national level was explicitly acknowledged as an important weakness of the national flood risk governance arrangement [15].

On the other hand, more room should be created for bottom-up activities: local and regional stakeholders (preferably at the river basin level) draft flood risk reduction plans together that are based on their objectives and are hereby supported with funding and expertise from the higher governments. Moreover, regions and municipalities should coordinate upstream and downstream measures. Multi-level governance is necessary because diversification of flood risk management approaches makes it very unlikely that a single governmental actor can oversee and implement 
complete portfolios of approaches. Multi-level governance is also necessary because often experiences at the local level, derived through pilots and experiments as in The Netherlands [16], hold valuable lessons that deserve upscaling. This requires some degree of coordination of experiments as well as translation and dissemination of their findings.

A key example of a bridging mechanism is the Flemish and Dutch water assessment, which intends to bridge water management and spatial planning [16,19]. Through the assessment, the impact of spatial planning actions on the water system, be it permits or plans and programs, are systematically scrutinized. Hence, flood risk managers can ensure that the strategies of flood risk prevention and flood mitigation are routinely considered in spatial planning processes, bringing together actors at the local level. Another prominent example is the designation of properties as at risk properties. For instance, England knows the duty of property owners to inform prospective buyers of flood risks. Belgium and France have procedures to designate flood zones, e.g., signal areas in Belgium and areas falling under the auspices of the PPRI (the national Plan de Prevention de Risk d'Inondation) in France. The designation of high-risk zones leads to additional requirements and restrictions in the Belgium case, while it might lead to the prohibition of urban development or at least severe restrictions to it in the case of France $[17,19]$.

\subsection{Increased Involvement of Private Actors, Including Businesses, NGOs, and Citizens in Addition to Strong Public Involvement}

In the European Union context, governmental actors are playing a strong role in establishing and maintaining vital infrastructure. These actors alone, however, cannot implement a comprehensive portfolio of flood risk management approaches. Hence, the involvement of private parties in flood risk governance, including businesses, Non Governmental Organisations (NGOs), and citizens, is necessary to enhance flood resilience. First, from a substantive viewpoint, the input of a diverse set of resources and capacities that are embodied in the expertise and knowledge of stakeholders is needed to implement a diverse set of flood risk management approaches as governmental institutions do not have all the necessary resources to cope with complex flood risks [9]. Second, from a normative perspective, participation in decision-making is considered important because participation enhances the legitimacy of measures that are taken to decrease flood risks and contributes to representative deliberation, procedural and distributive justice, and socio-political acceptability [30].

Private sector involvement is needed to strengthen all three capacities. Measures that enhance the capacity to absorb and recover cannot be taken by governmental actors alone, while enhancing the capacity to adapt and transform inherently necessitates the involvement of a broad set of societal actors. Think of house-owners who need to make their houses flood-proof and insurance companies that need to activate flood prevention more.

Companies can contribute to flood risk governance through public-private cooperation. A good practice in this respect is the English Partnership Funding Scheme which obliges local authorities, the private sector, or civil society to match national government funding. Thus, actors with a financial stake in flood risk management that have not been previously actively involved can enter into the governance strategies at the project level [14]. Countries which have private flood insurance mechanisms require cooperation between public and private actors, since public actors are often the reinsurers of the last resort.

Citizens in their capacity of residents can take actions in and around their homes. First, new houses should be built to be flood-proof. The implementation of property level measures such as the (dry or wet) flood-proofing of houses or the creation of capacity for rainwater retention (through green roofs and other infiltration capacities) can complement actions that are also taken by governmental actors. Citizen involvement in these cases may be necessary for substantive reasons (e.g., because measures are taken on private properties), however also for normative reasons (e.g., because citizens should have a say in issues in which they have a stake or out of the 'beneficiary pays' principle, i.e., the 
belief that those benefitting should implement measures [31]). That is why co-production between citizens and governmental actors is increasingly called for.

In a European context, however, we see that public authorities have traditionally taken the lead in flood risk management and are struggling with how to best engage citizens. There is a tendency for citizens to adopt a paternalistic "the-government-should-take-care-of-me" attitude, while communicating flood risks to citizens and companies is made difficult by the highly technical language of flood managers, which is poorly understood by the public or is poorly communicated [32]. A prime example is the involvement of citizens in fluvial flood risks in The Netherlands. While flood consequences in The Netherlands are relatively large, there is a serious lack of flood awareness and corresponding action being possible or taken by residents $[16,33]$ that is only changing gradually. However, the lack of action being taken can to some extent be explained out of a lack of action perspectives, e.g., in areas in which possible inundation depths are high and flooding occurs fast. In their efforts to co-produce with citizens, governmental actors are focusing mainly on pluvial flooding [31]. Engagement of residents in flood risk governance seems to be highest in England [14] and Poland where Voluntary Fire Brigades have an important role in flood preparation [18]. In England, this seems to be directly related to the fact that the country has already diversified its portfolio of flood risk management strategies, combined with dedicated measures that lead to flood consciousness such as awareness campaigns by the Environment Agency (Bristol, UK). The frequent floods of the past years have undoubtedly contributed to this level of flood awareness. In Poland, the relatively high level of flood awareness seems to be more directly attributable to the occurrence of devastating floods, most notably that of 1997 [18]. In terms of involving residents in co-producing flood risk management, Belgium, France, and Sweden seem to rank between these extremes.

\subsection{Adequate Formal Rules that Balance Legal Certainty and Flexibility}

Flood risk governance requires a delicate balancing act between legal certainty-that is the assurance that one's rights are clear and will be respected-and flexibility which might be necessary for adaptive governance [34,35]. To establish the different resilience capacities, both are needed to some extent.

Legal certainty means that decisions are based in law and are possible to foresee. There are differences in the degree to which individuals in the different countries are sure of their rights and to what extent actions/decisions in respect of these rights can be predicted. Legal certainty is required to achieve clarity about responsibilities amongst public authorities and communities, for instance about what level of flood protection can be ensured or aimed for and who is responsible for this. It furthermore provides clarity on the scope of formal powers based on the several relevant policy fields, the legal instruments that are available, and the legal basis for taxes, insurance schemes, and compensation to be used for flood risk management. Hence, legal certainty provides much needed structure and guidance, which is a necessary precondition for achieving sufficient capacity to resist as well as to absorb and recover. Land-use planning can, for instance, be used to keep people away from the water, i.e., steer development away from flood prone zones. However, the legal certainty provided by land-use plans differs between the various countries. In Sweden, only detailed plans (zoning) are legally binding for individuals and there are no mechanisms to ensure their implementation, while in The Netherlands, land-use or spatial plans are legally binding and provide certainty regarding the possibilities to use land and property for diverse functions. It is, for example, not possible to change the function of agricultural land towards a flood retention area without a formal change of the designated function that the land use may have in a spatial plan and often also involves related compensation for the land owner. The same goes for Room for the River projects and dike reinforcement projects, as rivers and dikes are being designated as such in a spatial plan. This protects citizens in that they know when and where they can expect changes in the possibilities to use their land. Regulating restrictions in land use-especially of private property - need explicit changes in land use plans (by means of a formal change of the plan itself or a formal permission to deviate from the plan) and related regulations 
in order to provide private actors legal certainty and to enable them to take investment decisions based on adequate information of their rights and responsibilities.

On the other hand, to achieve a high capacity to adapt and transform, formal rules should also provide enough flexibility to enable tailored local approaches and adaptive pathways whereby a change in course is possible if dynamics require it, e.g., due to urbanization or climate change patterns. At the same time, we face the challenge of not sacrificing legal certainty, including the possibility to hold public authorities accountable [34]. Flexibility and the possibility to adapt because of changing circumstances is generally provided by multiple year planning cycles, for example, the six year planning cycle of water plans in The Netherlands. A new planning period should take new circumstances into account and should mention the proposed measures for the coming years, thus providing insight into new policies and possible restrictions for citizens. As the preparation of new plans takes place with participation of the public, more adaptive and still legitimate policies can be introduced. Long-term strategic planning combined with short-term operational planning provides citizens with clarity on what can be expected in the near future. The issue of legal certainty versus flexibility is ubiquitous and is typically "solved" on a case-to-case basis. Some laws and legal rules are said to be "better" than others in this respect, for example, performance based rules, since these imply both requirements and flexibility in implementation. The possibility to appeal and revoke (plan) decisions is, however, an important feature of a flexible system that still adheres to the principle of (procedural) legal certainty. In Sweden, this is legally possible, however it is unusual due to the municipal planning monopoly.

In Europe, the establishment of formal rules is taking place both at the European Union (EU) and at the national level. At the former level, in 2007, the Directive 2007/60/EC on the assessment and management of flood risks (Floods Directive or FD) was introduced. This is widely seen as an important step towards establishing a minimum common flood management framework. The FD obliges EU Member States to establish flood risk assessments; draw flood hazard and flood risk maps and make flood risk management plans that should be revised every six years. The main consideration that drove the establishment of a European approach was to ensure international solidarity amongst other rules by mandating that measures do not significantly increase risk to societies elsewhere [36]. The FD has been effective in establishing greater discussion and consideration of flood issues, particularly in those countries where flood management was underdeveloped. There are, furthermore, instances whereby the FD has stimulated improvements in regional, national, and transboundary flood risk management and cooperation [36-38].

The FD takes a procedural approach and leaves the Member States a large amount of policy discretion about how they want to design flood risk management. It takes flexibility and subsidiarity as the main points of departure. However, both the nature and implementation of the FD lead to concerns about its ability to achieve its aims. An important lesson is that its lack of substantive requirements and strong reliance on procedural obligations might undermine its ability to lead to increased flood resilience [34-36]. The FD may serve as a good practice to develop a comprehensive overview of flood risks, which enables decision-makers and the broad public to be aware of the risk in their living environment. The cyclic planning and programming approach with plans and programs that must be revised every six years makes it possible to adapt and learn. The FD may help to decrease external effects, despite the differing political, legal, and policy contexts that are present. It is a policy choice whether the legal framework for flood risk governance should embody only a procedural or also a substantive approach. The advantage of a purely procedural approach is that it respects the different geographical conditions and leaves policy discretion to the individual states in terms of how much and in what ways they want to improve flood risk governance. However, clear definitions are necessary to ensure the coherent implementation of flood risk governance frameworks, especially in the case of transboundary river basins $[39,40]$. The advantage of a combined procedural and substantive approach is that there is also more clarity about the level of protection that will be offered and about who is responsible for the design, development, and implementation, adding to legal certainty. As of now, 
this is not the path taken in the approach that is laid down in the Floods Directive, which through its procedural approach, can be seen as non-committal. The lack of substantive requirements implies that individuals cannot rely on the Directive directly, however they are referred to the discretion of the national legislation and the way that the national courts deal with this [36]. The differences between the several Member States that are part of the research are significant. The Netherlands has legally binding safety standards that provide clarity on the scope of the governmental responsibilities for flood protection. The other countries do not have these standards and citizens should determine the level of flood protection and the scope of their private responsibilities in a more indirect way by interpreting policy documents.

\subsection{The Assurance of Sufficient Resources}

Diversification of flood risk management strategies requires resources, including finances, knowledge, and capacities, that are possibly formalized in legislation, for example, when flood protection is paid from general or designated taxes [4-44]. Flood resilience will be stimulated when sufficient and satisfactory resources are mobilized and dedicated to multiple flood risk management approaches. Resources channeled into one approach should not lead to underinvestment in other approaches. This will to some extent entail a reallocation of resources [20]. In this regard, we see two important developments that, from a resilience perspective, provide opportunities and risks: private investments and decentralization. These may help to broaden the resource base of flood risk management.

In Europe, typically the nation state and general tax income play the principal role in flood risk management. The nation state is also responsible for the education of experts and providing legal frameworks for management. In many countries, financial resources for flood risk management have been under pressure, in particular after the 2008 crisis, due to central budget constraints. Involvement of local governments, businesses (e.g., insurance), communities, and household owners is, however, increasing. At the same time, an increasing appeal is being made to local governments as well as private actors to take up more responsibility in flood risk management [9]. From a resilience perspective, this has, in principle, the advantage that the resource base is broadened and that locally tailored approaches are enabled, strengthening the capacity to adapt and transform and the capacity to absorb and recover. However, decentralization as well as reliance on private investments is not without risks. A lack of funds and expertise at the level of local communities can limit the development of approaches [42]. It may also have distributional effects and justice implications in that it is often economically marginalized groups and territories that suffer from floods. There may also be a financial incentive for local governments to permit spatial developments in at-risk areas [9,42].

In The Netherlands, for example, protection against floods is strongly based on the solidarity principle, as every person in a certain area has the same level of protection. Resources are provided by taxes from the regional water authorities combined with funding by general taxes. Investments that have to be made for dike reinforcements or flood retention areas include the costs to compensate those who suffer more than others because the measures will make use of their private property [28].

In terms of resources, in The Netherlands, the division of resources mirrors the relative importance that is attached to flood defense, with many financial resources going to large dike strengthening projects for which a special fund has been designated (https:/ / www.infomil.nl/onderwerpen/luchtwater/handboek-water/wetgeving/waterwet/financiele/deltafonds/), while maintenance is paid from tax revenues of regional water authorities. This notwithstanding, as part of the Delta program, pilots at the local level are also taking place, leading to the additional development of knowledge and expertise and the exchange of experiences. England has had a long-standing approach to funding flood risk management from central government funds through a dedicated budget. This commitment has been a stabilizing factor and consistent investment has led to the incremental improvement of flood risk management (FRM) which was further strengthened in 2015 through the adoption of a 6-year investment program [45]. Funds are allocated to areas using economic prioritization and it recognizes 
the management principle that resources are limited and not all risks can be avoided. From 2012, a new Partnership Funding approach was adopted [46] which aims to raise a proportion of the funds locally, thereby placing a higher burden of those benefitting from FRM (and questions remain about fairness and the success of delivery) [14], however increasing the overall investment for FRM and permitting more management measures to be funded.

\subsection{Appropriate Normative Principles for Dealing with Distributional Effects}

The governance of risk bestows benefits and imposes burdens in several ways [42] as virtually all measures and policies have distributional effects [28,47-49]. The development towards a diversification of flood risk management approaches will probably be no exception. A consequence might for instance be an increased financial burden for at-risk households $[48,49]$ or for agricultural businesses that are confronted with restrictions in crop use because of Room for the River projects based on new restrictions in land-use plans or the designation and use of flood retention areas. Another consequence might be a transfer of safety/money between upstream and downstream communities and 'privatization' of responsibilities to non-stake actors and stakeholders [50,51]. While in principle inequity in the distribution of the benefits and burdens can be dealt with through targeted actions [28], in reality it might prove difficult to identify vulnerable groups and to design instruments with the desired effect. Because of this, resilient flood risk governance requires mechanisms to ensure social equity and to address 'unfair' distributional effects. The Netherlands has a strong history in dealing with distributional effects, while, for example, France and Belgium show different approaches depending on whether measures are based on spatial planning or water management [49]. This might lead to a choice for a flood risk management measure that increases the unequal distribution of burdens or, on the contrary, a choice that best suits fairness in flood risk management. Examples of different mechanisms with different underlying normative principles are: (i) the partnership funding in England which encourages local actors and stakeholders to engage in FRM and facilitates flood defense schemes; (ii) the constitutional right to flood protection in The Netherlands which is enacted through legal safety standards based on risk type [30]; (iii) compensation regimes/schemes which increase equity, and mechanisms for compensating losses. These are present in most of the researched countries [52].

To put such mechanisms in place, inclusive societal debates are needed that lead to the establishment of adequate normative principles that are seen as fair and legitimate [9]. Depending on the (national) context, different principles may be preferred. Whereas from a solidarity perspective it would be considered fair that people in low risk areas also contribute to flood protection measures, if fairness is interpreted as 'beneficiary pays', the situation will be perceived as fair if contributions are based on risks or on benefits [53]. Another principle that could be applied is to give priority to measures that protect the most vulnerable people [54] in those countries that do not take solidarity and protection for all as the basis for their flood risk policies. It seems that approaches presuppose different normative systems. Flood defenses which have a public good character seem to be based on the solidarity principle. At the same time, a market-based system can still be based on the solidarity principle [55], such as in France. To increase the acceptability of flood risk management measures, debates on what is seen as desirable and how and to what extent different strategies may help to realize these normative ideals should be held in the open rather than be restricted to a selective number of public officials and experts $[9,53]$. Diversification of flood risk management strategies might serve as a mechanism to open up such debates, since it implies that flood managers have to make a shift from highly technical jargon towards more lay language.

\section{Discussion and Conclusions}

The current paper has addressed an important knowledge gap in that governance and legal knowledge on flood risk management was relatively limited and fragmented until recently. While the number of studies in this field has increased over the years, the step towards the identification of overall governance strategies that can be deemed applicable in multiple contexts had not yet been 
taken. The six governance strategies laid down in this paper have addressed this gap. Besides that, we further elaborated a visualized categorization of five modes of flood risk management (flood risk prevention, flood defence, flood mitigation, flood preparation, and flood recovery). The distinction between these five modes might form a precious source for teaching and for the improvement of the awareness of policy makers and possibly also citizens in order to enhance their involvement in flood risk governance.

In a fully flood-resilient society, the three resilience capacities (capacity to resist, to absorb and recover, and to adapt and transform) are sufficiently present and well-aligned to increase effectiveness. In practice, however, countries make trade-offs and focus flood risk governance efforts on specific capacities, leading to differences in countries' strengths and weaknesses regarding flood resilience. For instance, England has all three capacities developed to a large extent, whereas The Netherlands is focusing much on the capacity to resist. Trade-offs are made based on normative starting points, physical circumstances (e.g., rainfall patterns, altitude and gradient of physical terrains, the degree of complexity of river systems), institutional and social contexts, and available resources [9]. However, well-elaborated choices are essential, taking diversification and alignment of flood risk management approaches as an important starting point.

Flood resilience also means the efficient use of resources (economic, human, technological), maximizing desired outputs and minimizing required inputs. (Societal) Cost Benefit Analysis [56] is considered to be a helpful tool to improve resource efficiency by selecting cost-efficient measures. Recent research also points to the usability of other financial tools that use Life Cycle Cost and Return on Investment as important decision variables [57].

Flood resilience can only be achieved when the legitimacy of governance strategies is not questioned: the input, process, and output should be legally legitimate and societally acceptable. Access to information and transparency, procedural justice, and accountability is well organized in the analyzed European countries, however there is room for improvement on the criteria of social equity, public participation, and acceptability by all actors that are involved [21]. These issues appear to be important in all countries that face huge flood risks.

The lessons derived from the STAR-FLOOD project have clearly shown that there is no concrete 'one size fits all' solution for achieving flood resilience. In that sense, there clearly is a limit to decentralization policies. Governance strategies should be specified and tailored to physical circumstances as well as institutional and social contexts. Nevertheless, the six governance strategies proposed in the current paper are a fruitful starting point for achieving such context-specific flood resilience. We maintain that these strategies have a wider meaning internationally. For instance, Tullos' [58] findings on the weaknesses of flood risk management in the USA strikingly apply to the European Union (EU), despite all the political, economic, and social differences between the two entities. Her call for reducing reliance on the structural measures resonates with the main finding of the STARFLOOD project that flood risk management strategies have to be diversified. The strategies proposed in this paper could also be relevant beyond Europe [59], for example, in several metropoles such as Bangkok, Mumbai, Jakarta, and Mexico City. These metropoles are in the front line of flood risk due to their overwhelming rate of urbanization and their lack of resources as compared to European metropolises.

In terms of the next steps, the six governance strategies point to important research themes that deserve to be considered further. Additional detailed case studies as well as studies in geographical regions other than Europe are necessary. These may help to further assess the relationship between governance and legal approaches and mechanisms and their outcomes in terms of flood risk reduction (the 'what works?' question). Issues to be taken up in this strand of research include the social and institutional mechanisms that facilitate or hamper the diversification of flood risk management strategies; the precise functioning and effectiveness of certain bridging mechanisms in different contexts; the mechanisms that may facilitate citizen co-production; and the types of resources that are present in different circumstances. At the same time, normative evaluations of flood risk governance are 
in order (the 'is it fair?' question), including the question of whether public debate on these questions is taking place. Assessments of these debates (e.g., through stakeholder analyses or argumentative discourse analyses) need to be related to institutionalization, e.g., in legal frameworks. We invite other scholars to join us in this exciting endeavor.

Author Contributions: The authors made the following contributions to the paper. Conceptualisation: P.P.J.D. and D.L.T.H. Methodology: all. Validation: all. Formal analysis: all. Investigation: all. Writing-original draft preparation: P.P.J.D. and D.L.T.H. Writing—review and editing: all. Visualization: G.T.R. Supervision: P.P.J.D. Funding acquisition: P.P.J.D., D.L.T.H., Z.W.K., H.F.M.W.v.R., A.C., C.L., M.P., G.T.R. and M.W.

Funding: This research was funded by the EUROPEAN COMMISSION within its Seventh Framework Programme through the grant to the budget of the Integrated Project STAR-FLOOD, Contract 308364. The APC was covered by the institution of the lead author.

Acknowledgments: The authors would like to acknowledge the researchers that were involved in the STAR-FLOOD project for the in-depth discussions that have helped to interpret the empirical material and translate these into six key governance strategies. Earlier drafts of this paper have been presented at the FLOODRISK 2016 conference in Lyon, the European Climate Change Adaptation (ECCA) conference in Glasgow (2017), and the Lund Conference on Earth System Governance (2017). The audiences of these conferences are acknowledged for their feedback. We finally thank Tina Newstead for her language corrections in earlier drafts of this paper.

Conflicts of Interest: The authors declare no conflict of interest. The funders had no role in the design of the study; in the collection, analyses, or interpretation of the data; in the writing of the manuscript, or in the decision to publish the results.

\section{References}

1. Kundzewicz, Z.W.; Krysanova, V.; Dankers, R.; Hirabayashi, Y.; Kanae, S.; Hattermann, F.F.; Huang, S.; Milly, P.C.D.; Stoffel, M.; Driessen, P.P.J.; et al. Differences in flood hazard projections in Europe-their causes and consequences for decision making. Hydrol. Sci. J. 2017, 62, 1-14. [CrossRef]

2. Kundzewicz, Z.W.; Kanae, S.; Seneviratne, S.I.; Handmer, J.; Nicholls, N.; Peduzzi, P.; Mechler, R.; Bouwer, L.M.; Arnell, N.; Mach, K.; et al. Flood risk and climate change: Global and regional perspectives [Le risque d'inondation et les perspectives de changement climatique mondial et régional]. Hydrol. Sci. J. 2014, 59, 1-28. [CrossRef]

3. Winsemius, H.C.; Aerts, J.C.J.H.; Van Beek, L.P.H.; Bierkens, M.F.P.; Bouwman, A.; Jongman, B.; Kwadijk, J.C.J.; Ligtvoet, W.; Lucas, P.L.; Van Vuuren, D.P.; et al. Global drivers of future river flood risk. Nat. Clim. Chang. 2016, 6, 381-385. [CrossRef]

4. Hansen, J.; Sato, M.; Ruedy, R. Perception of climate change. Proc. Natl. Acad. Sci. USA 2012, 109, E2415-E2423. [CrossRef] [PubMed]

5. Arthur, R.; Boulton, C.A.; Shotton, H.; Williams, H.T.P. Social sensing of floods in the UK. PLoS ONE 2018, 13, e0189327. [CrossRef] [PubMed]

6. Messeri, A.; Morabito, M.; Messeri, G.; Brandani, G.; Petralli, M.; Natali, F.; Grifoni, D.; Crisci, A.; Gensini, G.; Orlandini, S. Weather-Related Flood and Landslide Damage: A Risk Index for Italian Regions. PLoS ONE 2015, 10, e0144468. [CrossRef] [PubMed]

7. Walker, B.; Holling, C.S.; Carpenter, S.R.; Kinzig, A. Resilience, adaptability and transformability in social-ecological systems. Ecol. Soc. 2004, 9, 5. [CrossRef]

8. Folke, C.; Carpenter, S.R.; Walker, B.; Scheffer, M.; Chapin, T.; Rockström, J. Resilience thinking: Integrating resilience, adaptability and transformability. Ecol. Soc. 2010, 15, 4. [CrossRef]

9. Hegger, D.L.T.; Driessen, P.P.J.; Wiering, M.; Van Rijswick, H.F.M.W.; Kundzewicz, Z.W.; Matczak, P.; Crabbé, A.; Raadgever, G.T.; Bakker, M.H.N.; Priest, S.J.; et al. Toward more flood resilience: Is a diversification of flood risk management strategies the way forward? Ecol. Soc. 2016, 21, 4. [CrossRef]

10. Hirabayashi, Y.; Mahendran, R.; Koirala, S.; Konoshima, L.; Yamazaki, D.; Watanabe, S.; Kim, H.; Kanae, S. Global flood risk under climate change. Nat. Clim. Chang. 2013, 3, 816-821. [CrossRef]

11. Dieperink, C.; Hegger, D.L.T.; Bakker, M.H.N.; Kundzewicz, Z.W.; Green, C.; Driessen, P.P.J. Recurrent Governance Challenges in the Implementation and Alignment of Flood Risk Management Strategies: A Review. Water Resour. Manag. 2016, 30, 4467-4481. [CrossRef]

12. Van den Brink, M.; Termeer, C.; Meijerink, S. Are Dutch water safety institutions prepared for climate change? J. Water Clim. Chang. 2011, 2, 272-287. [CrossRef] 
13. Jongman, B.; Winsemius, H.C.; Aerts, J.C.J.H.; Coughlan De Perez, E.; Van Aalst, M.K.; Kron, W.; Ward, P. Declining vulnerability to river floods and the global benefits of adaptation. Proc. Natl. Acad. Sci. USA 2015, 112, E2271-E2280. [CrossRef] [PubMed]

14. Alexander, M.; Priest, S.; Micou, A.P.; Tapsell, S.; Green, C.; Parker, D.; Homewood, S. Analysing and Evaluating Flood Risk Governance in England-Enhancing Societal Resilience through Comprehensive and Aligned Flood Risk Governance; STAR-FLOOD Consortium: Utrecht, The Netherlands, 2016; ISBN 978-94-91933-07-3.

15. Ek, K.; Goytia, S.; Pettersson, M.; Spegel, E. Analysing and Evaluating Flood Risk Governance in Sweden-Adaptation to Climate Change? STAR-FLOOD Consortium: Utrecht, The Netherlands, 2016; ISBN 978-94-91933-10-3.

16. Kaufmann, M.; Van Doorn-Hoekveld, W.J.; Gilissen, H.K.; Van Rijswick, H.F.M.W. Drowning in Safety. Analysing and Evaluating Flood Risk Governance in The Netherlands; STAR-FLOOD Consortium: Utrecht, The Netherlands, 2016; ISBN 978-94-91933-11-0.

17. Larrue, C.; Bruzzone, S.; Lévy, L.; Gralepois, M.; Schellenberger, T.; Trémorin, J.B.; Fournier, M.; Manson, C.; Thuillier, T. Analysing and Evaluating Flood Risk Governance in France: From State Policy to Local Strategies; STAR-FLOOD Consortium: Utrecht, The Netherlands, 2016; ISBN 978-94-91933-08-0.

18. Matczak, P.; Lewandowski, J.; Choryński, A.; Szwed, M.; Kundzewicz, Z.W. Flood Risk Governance in Poland: Looking for Strategic Planning in a Country in Transition; STAR-FLOOD Consortium: Utrecht, The Netherlands, 2016; ISBN 978-94-91933-09-7.

19. Mees, H.; Suykens, C.; Beyers, J.C.; Crabbé, A.; Delvaux, B.; Deketelaere, K. Analysing and Evaluating Flood Risk Governance in Belgium. Dealing with Flood Risks in an Urbanised and Institutionally Complex Country; STAR-FLOOD Consortium: Utrecht, The Netherlands, 2016; ISBN 978-94-91933-06-6.

20. Hegger, D.L.T.; Driessen, P.P.J.; Bakker, M.H.N. A View on More Resilient Flood Risk Governance: Key Conclusions of the STAR-FLOOD Project; STAR-FLOOD Consortium: Utrecht, The Netherlands, 2016; ISBN 978-94-91933-13-4.

21. Raadgever, G.T.; Hegger, D.L.T. Flood Risk Management Strategies and Governance; Springer: Berlin, Germany, 2018; ISBN 978-331967699-9.

22. Aerts, J.C.J.H.; Botzen, W.; Van der Ven, A.; Krywkow, J.; Werners, S. Dealing with uncertainty in flood management through diversification. Ecol. Soc. 2008, 13, 41. [CrossRef]

23. Hegger, D.L.T.; Driessen, P.P.J.; Dieperink, C.; Wiering, M.; Raadgever, G.T.; Van Rijswick, H.F.M.W. Assessing stability and dynamics in flood risk governance: An empirically illustrated research approach. Water Resour. Manag. 2014, 28, 4127-4142. [CrossRef]

24. Thampapillai, D.J.; Musgrave, W.F. Flood damage mitigation: A review of structural and nonstructural measures and alternative decision frameworks. Water Resour. Res. 1985, 21, 411-424. [CrossRef]

25. Van Buuren, A.; Ellen, G.J.; Warner, J.F. Path-dependency and policy learning in the Dutch delta: Toward more resilient flood risk management in The Netherlands? Ecol. Soc. 2016, 21, 43. [CrossRef]

26. Gilissen, H.K.; Alexander, M.; Beyers, J.-C.; Chmielewski, P.; Matczak, P.; Schellenberger, T.; Suykens, C.B.R. Bridges over troubled waters: An interdisciplinary framework for evaluating the interconnectedness within fragmented domestic flood risk management systems. J. Water Law 2015, 25, 12-26.

27. Suykens, C.; Priest, S.J.; Van Doorn-Hoekveld, W.J.; Thuillier, T.; Van Rijswick, M. Dealing with flood damages: Will prevention, mitigation, and ex post compensation provide for a resilient triangle? Ecol. Soc. 2016, 21, 1. [CrossRef]

28. Van Doorn-Hoekveld, W.J. Distributional Effects of EU Flood Risk Management and the Law. Ph.D. Thesis, Utrecht University, Utrecht, The Netherlands, 2018.

29. Kolen, B.; Helsloot, I. Decision-making and evacuation planning for flood risk management in The Netherlands. Disa 2014, 38, 610-635. [CrossRef] [PubMed]

30. Alexander, M.; Doorn, N.; Priest, S. Bridging the legitimacy gap-Translating theory into practical signposts for legitimate flood risk governance. Reg. Environ. Chang. 2018, 18, 397-408. [CrossRef]

31. Mees, H.; Crabbé, A.; Alexander, M.; Kaufmann, M.; Bruzzone, S.; Lévy, L.; Lewandowski, J. Coproducing flood risk management through citizen involvement: Insights from cross-country comparison in Europe. Ecol. Soc. 2016, 21, 7. [CrossRef]

32. Klijn, F.; Samuels, P.; Van Os, A. Towards flood risk management in the EU: State of affairs with examples from various European countries. Int. J. River Basin Manag. 2008, 6, 307-321. [CrossRef] 
33. OECD. Water Governance in The Netherlands: Fit for the Future? OECD Studies on Water; OECD Publishing: Paris, France, 2014.

34. Goytia, S.; Pettersson, M.; Schellenberger, T.; Van Doorn-Hoekveld, W.J.; Priest, S. Dealing with change and uncertainty within the regulatory frameworks for flood defense infrastructure in selected European countries. Ecol. Soc. 2016, 21, 23. [CrossRef]

35. Green, O.O.; Garmestani, A.S.; Van Rijswick, H.F.M.W.; Keessen, A.M. EU water governance: Striking the right balance between regulatory flexibility and enforcement? Ecol. Soc. 2013, 18, 10. [CrossRef]

36. Priest, S.J.; Suykens, C.; Van Rijswick, H.F.M.W.; Schellenberger, T.; Goytia, S.; Kundzewicz, Z.W.; Van Doorn-Hoekveld, W.J.; Beyers, J.-C.; Homewood, S. The European union approach to flood risk management and improving societal resilience: Lessons from the implementation of the Floods Directive in six European countries. Ecol. Soc. 2016, 21, 50. [CrossRef]

37. Suykens, C.B.R. The Law of the River. The Institutional Challenge for Transboundary River Basin Management and Multi-Level Approaches to Water Quantity Management. Ph.D. Thesis, Utrecht University, Utrecht, The Netherlands, 2017.

38. Suykens, C. EU water quantity management in international river basin districts: Crystal clear? Eur. Energy Environ. Law Rev. 2015, 24, 134-143.

39. Keessen, A.M.; Van Rijswick, H.F.M.W. Adaptation to climate change in European water law and policy. Utrecht Law Rev. 2012, 8, 38-50. [CrossRef]

40. Keessen, A.M.; Van Kempen, J.J.H.; Van Rijswick, M.; Robbe, J.; Backes, C.W. European river basin districts: Are they swimming in the same implementation pool? J. Environ. Law 2010, 22, 197-221. [CrossRef]

41. Gralepois, M.; Larrue, C.; Wiering, M.; Crabbé, A.; Tapsell, S.; Mees, H.; Ek, K.; Szwed, M. Is flood defense changing in nature? Shifts in the flood defense strategy in six European countries. Ecol. Soc. 2016, 21, 37. [CrossRef]

42. Fournier, M.; Larrue, C.; Alexander, M.; Hegger, D.; Bakker, M.; Pettersson, M.; Crabbé, A.; Mees, H.; Chorynski, A. Flood risk mitigation in Europe: How far away are we from the aspired forms of adaptive governance? Ecol. Soc. 2016, 21, 49. [CrossRef]

43. Gilissen, H.K.; Alexander, M.; Matczak, P.; Pettersson, M.; Bruzzone, S. A framework for evaluating the effectiveness of flood emergency management systems in Europe. Ecol. Soc. 2016, 21, 27. [CrossRef]

44. Thieken, A.H.; Kienzler, S.; Kreibich, H.; Kuhlicke, C.; Kunz, M.; Mühr, B.; Müller, M.; Otto, A.; Petrow, T.; Pisi, S.; et al. Review of the flood risk management system in Germany after the major flood in 2013. Ecol. Soc. 2016, 21, 51. [CrossRef]

45. Environment Agency. Flood and Coastal Erosion Risk Management in England: Investment Programme 2015 to 2021; EA: Bristol, UK, 2018.

46. Department for Environment, Food and Rural Affairs (Defra). Flood and Coastal Resilience Partnership Funding. Defra Policy Statement on an Outcome-Focused, Partnership Approach to Funding Flood and Coastal Erosion Risk Management; Department for Environment, Food and Rural Affairs (Defra): London, UK, 2011.

47. Lazarus, R. Pursuing Environment Justice: The Distributional Effects of Environmental Protection. Nw. UL Rev. 1992, 87, 787.

48. Van Doorn-Hoekveld, W. Transboundary flood risk management: Compatibilities of the legal systems of flood risk management in The Netherlands, Flanders and France-A comparison. Eur. Energy Environ. Law Rev. 2017, 26, 81-96.

49. Van Doorn-Hoekveld, W. Equal distribution of burdens in flood risk management-The application of the 'égalité principle' in the compensation regimes of The Netherlands, Flanders and France. Rev. Eur. Adm. Law 2017, 10, 81-110. [CrossRef]

50. Thaler, T.; Hartmann, T. Justice and flood risk management: Reflecting on different approaches to distribute and allocate flood risk management in Europe. Nat. Haz. 2016, 83, 129-147. [CrossRef]

51. Van Rijswick, H.F.M.W.; Havekes, H.J.M. European and Dutch Water Law; Europa Law Publishing: Groningen, The Netherlands, 2012; ISBN 9789089521071.

52. Van Doorn-Hoekveld, W.J.; Goytia, S.B.; Suykens, C.; Homewood, S.; Thuillier, T.; Manson, C.; Chmielewski, P.; Matczak, P.; Van Rijswick, H.F.M.W. Distributional effects of flood risk management-A cross-country comparison of preflood compensation. Ecol. Soc. 2016, 21, 26. [CrossRef]

53. Penning-Rowsell, E.; Pardoe, J. The distributional consequences of future flood risk management in England and Wales. Environ. Plan. C 2015, 33, 1301-1321. [CrossRef] 
54. Doorn, N. Resilience indicators: Opportunities for including distributive justice concerns in disaster management. J. Risk Res. 2017, 20, 711-731. [CrossRef]

55. Pettersson, M.; Van Rijswick, M.; Suykens, C.; Alexander, M.; Ek, K.; Priest, S. Assessing the legitimacy of flood risk governance arrangements in Europe: Insights from intra-country evaluations. Water Int. 2017, 42, 929-944. [CrossRef]

56. Rojas, R.; Feyen, L.; Watkiss, P. Climate change and river floods in the European Union: Socio-economic consequences and the costs and benefits of adaptation. Glob. Environ. Chang. 2013, 23, 1737-1751. [CrossRef]

57. De Risi, R.; De Paola, F.; Turpie, J.; Kroeger, T. Life Cycle Cost and Return on Investment as complementary decision variables for urban flood risk management in developing countries. Int. J. Disaster Risk Reduct. 2018, 28, 88-106. [CrossRef]

58. Tullos, D. How to achieve better flood-risk governance in the United States. Proc. Natl. Acad. Sci. USA 2018, 115, 3731-3734. [CrossRef] [PubMed]

59. Dai, L.; Van Doorn-Hoekveld, W.J.; Yu Wang, R.; Van Rijswick, H.F.M.W. Dealing with distributional effects of flood risk management in China: Compensation mechanisms in flood retention areas. under review.

(C) 2018 by the authors. Licensee MDPI, Basel, Switzerland. This article is an open access article distributed under the terms and conditions of the Creative Commons Attribution (CC BY) license (http://creativecommons.org/licenses/by/4.0/). 